\title{
Hematopoietic-Prostaglandin D2 synthase through PGD2 production is involved in the adult ovarian physiology
}

\author{
Andalib Farhat ${ }^{1}$, Pascal Philibert ${ }^{1,2}$, Charles Sultan ${ }^{1,2}$, Francis Poulat ${ }^{1}$, Brigitte Boizet-Bonhoure ${ }^{1 *}$
}

\begin{abstract}
Background: The prostaglandin D2 (PGD2) pathway is involved in numerous biological processes and while it has been identified as a partner of the embryonic sex determining male cascade, the roles it plays in ovarian function remain largely unknown. PGD2 is secreted by two prostaglandin D synthases (Pgds); the male-specific lipocalin (L)Pgds and the hematopoietic (H)-Pgds.

Methods: To study the expression of the Pgds in the adult ovary, in situ hybridization were performed. Then, to evaluate the role of $\mathrm{H}$-Pgds produced PGD2 in the ovarian physiology, adult female mice were treated with HQL79, a specific inhibitor of H-Pgds enzymatic activity. The effects on expression of the gonadotrophin receptors FshR and LhR, steroidogenic genes Cyp11A1, StAR and on circulating progesterone and estradiol, were observed.

Results: We report the localization of H-Pgds mRNA in the granulosa cells from the primary to pre-ovulatory follicles. We provide evidence of the role of H-Pgds-produced PGD2 signaling in the FSH signaling through increased FshR and LhR receptor expression. This leads to the activation of steroidogenic Cyp 11A1 and StAR gene expression leading to progesterone secretion, independently on other prostanoid-synthetizing mechanisms. We also identify a role whereby H-Pgds-produced PGD2 is involved in the regulation of follicular growth through inhibition of granulosa cell proliferation in the growing follicles.
\end{abstract}

Conclusions: Together, these results show PGD2 signaling to interfere with FSH action within granulosa cells, thus identifying an important and unappreciated role for PGD2 signaling in modulating the balance of proliferation, differentiation and steroidogenic activity of granulosa cells.

\section{Background}

Folliculogenesis is under the control of growth factors and two pituitary gonadotropin hormones; folliclestimulating hormone (FSH) and luteinizing hormone $(\mathrm{LH})$. These heterodimeric glycoproteins bind in the ovary to specific G-protein coupled receptors, FshR and LhR respectively, to facilitate the growth and differentiation of ovarian cells and also to control the production of the two steroid hormones estradiol and progesterone, for review see [1,2].

Amongst the several autocrine and/or paracrine growth factors produced by the follicle itself, prostaglandins are critical for multiple stages of reproduction [3,4].

\footnotetext{
* Correspondence: boizet@igh.cnrs.fr

'Institut de Génétique Humaine, Department of Genetic and Development, CNRS UPR1142, 141, rue de la Cardonille, 34396 Montpellier CEDEX5, France Full list of author information is available at the end of the article
}

Mice lacking the cyclo-oxygenase-2 (Cox-2) gene encoding the rate limiting step in prostaglandin synthesis, show pre-implantation deficiencies throughout ovulation and fertilization [5]. This phenotype is also seen in the absence of prostaglandin E2 (PGE2) receptor EP2 [6]. A surge in LH levels in granulosa cells of pre-ovulatory follicles induces expression of Cox-2 and EP2 [7], while elevated PGE2 in turn, stimulates cumulus expansion by elevating cAMP [8]. It has also been shown that PGE2 increases expression of the aromatase Cyp19A1 gene, the key gene in estrogen biosynthesis in granulosa cells [9], as well as acting as a luteotrophic component to stimulate luteal progesterone secretion through a cAMP-mediated pathway in both human and ruminants [10]. Besides PGE2, prostaglandin PGF2 $\alpha$ secretion via cyclo-oxygenase COX-1 expression and the action of its receptor $\mathrm{FP}$, also plays an important role in diminishing

\section{Biomed Central}


progesterone levels and stimulating luteolysis, a crucial stage in inducing labor and pup delivery during parturition in human and mice $[11,12]$. Whereas PGE2 and PGF2 $\alpha$ are both involved in regulating ovulation, luteinization, luteolysis and fertility [13-16], the role(s) of PGD2 signaling in folliculogenesis and ovarian physiology is not precisely understood.

PGD2 has been implicated as a signaling molecule in the mediation or regulation of various biological processes such as platelet aggregation, broncho-constriction and allergic diseases $[17,18]$, whilst also being identified as a partner of the embryonic sex-determining male cascade $[19,20]$. Secreted PGD2 interacts with two receptors: (i) the specific membrane-bound DP receptor (DP1) associated with adenylcyclase and intracellular cAMP production [21,22], and (ii) chemo attractant receptor Th2 (CRTH2) cells (DP2) which is coupled to $\mathrm{Ca}^{2+}$ signaling. A metabolite of PGD2, PGJ2, has also been shown to bind the peroxisome proliferatoractivated receptor PPAR $\gamma$ a member of the orphan nuclear receptor superfamily implicated in key female reproductory roles [23]. PGD2 is produced by two prostaglandin D synthases (Pgds) responsible for mediating the final regulatory step in the biosynthetic pathway of PGD2 production [24]: (i) the lipocalin-type Pgds (LPgds), a member of the lipocalin ligand-carrier protein family $[24,25]$ and (ii) the hematopoietic-type Pgds (HPgds) or GSH-requiring enzyme [26].

The L-Pgds transcript initially found in the brain [27], represents one of the ten most abundant transcripts in the cortex, hypothalamus and pituitary gland [28]. However, it is not expressed in either the embryonic or the adult ovary $[20,29,30]$ whereas $H$-Pgds is expressed in the embryonic gonad of both sexes (submitted data). H-Pgds is a cytosolic protein responsible for the biosynthesis of PGD2 in immune and inflammatory cells such as mast cells or Th2 cells, and is also expressed in the spleen, thymus, skin and liver [26], in the microglia where H-Pgdsproduced PGD2 is responsible for the neuroinflammation associated with brain injury and neurodegenerative diseases [31], as well as in trophoblasts, uterine epithelium and endometrial glands at the implantation site of the human decidua [32]. H-Pgds expression was also found in the hypothalamus-pituitary axis of hens and has been associated with high egg production [33]. Recently, PGD2 produced by H-Pgds and its metabolite PGJ2 have been shown to induce transcription of the $L h b$ subunit gene in the primary culture of chicken anterior pituitary cells, via the PPAR $\alpha$ and PPAR $\gamma$ signaling pathways [34]. On the other hand, a stimulatory effect of PGD2 on progesterone secretion has been found in vitro in isolated human corpus lutea [35]. However, the precise $H$-Pgds expression profile and function of PGD2 signaling in the adult ovary remain unknown.
Here, we report the characterization and ovarian localization of $\mathrm{H}$-Pgds mRNA and provide evidence of a role of H-Pgds-produced PGD2 signaling in the FSH signaling via the increase of $F s h R$ and $L h R$ receptor expression, leading to activation of steroidogenic Cyp11A1 and StAR gene expression and progesterone secretion. We found that in vivo inhibition of $\mathrm{H}$-Pgds activity failed to modify PGE2 and PGF2 $\alpha$ synthesis in the ovary and also identify a role for H-Pgds-produced PGD2 in follicular growth regulation. Our results provide evidence that PGD2 signaling is a modulator of the differentiation and steroidogenic activity of granulosa cells.

\section{Methods}

\section{Mouse strain and treatments}

Female C57BL/6J mice (Charles River Laboratories, Saint Germain sur l'Arbresle, France) were housed at the IGH animal care facility under controlled environmental conditions (12 h light/12 h darkness, temperature $21^{\circ} \mathrm{C}$ ). Animal care and handling conformed to the Réseau des Animaleries de Montpellier (RAM) and all procedures were approved by the Languedoc-Roussillon Regional Ethic committee (permit number 34-366, 2008 to $\mathrm{BBB})$.

HQL-79 (4-benzhydryloxy-1-[3-(1H-tetrazol-5yl)-propylpiperidine) [36], an inhibitor of H-Pgds activity, was purchased from Cayman Chemical (SpiBio, Interchim Montluçon, France). A HQL-79 solution (2.5 $\mathrm{mg} / \mathrm{ml}$ ) was made in methanol as recommended by the supplier and diluted to $0.125 \mathrm{mg} / \mathrm{ml}$ in $0.6 \%$ saline solution. Daily oral administration of HQL-79 was performed on 8 weeks old- cycling female mice for 5 to 9 days (for ovaries analyzis at the estrous phase) or for 16 days (for study of the length of the estrous cycle (three to four cycles)), as mentioned in the text. According to previous studies [36-38], $0.1,1$ or $10 \mathrm{mg} / \mathrm{kg} /$ day were administrated for the first experiment and then $1 \mathrm{mg} / \mathrm{kg} /$ day was administrated in the following experiments since the three doses had the same impact on the expression of ovarian markers. As a control, the same volume of vehicle $(0.5 \%$ methanol $)$ was orally administrated into control cycling mice during the same period.

Young cycling female mice (6 weeks) were treated with 5 I. U. PMSG (pregnant mare serum gonadotropin, Sigma-Aldrich, St Louis, MO, USA) without or with administration of HQL-79 inhibitor (1 mg/kg/day). PMSG was dissolved in $0.6 \%$ saline solution and injected s.c. in a total volume of $0.1 \mathrm{ml}$, at the diestrous or proestrous stages of the cycle to initiate follicular development. Ovaries were dissected $48 \mathrm{~h}$ later for analysis.

\section{Determination of estrous cycle}

To determine the stages of estrous cycle, vaginal washes were collected for 16 days (three to four cycles) from 
five wild type (WT) and five HQL-79 mice. Diestrous phase was defined by the exclusive presence of leukocytes; proestrous phase by leukocytes and nucleated epithelial cells; estrous phase by large and squamoustype epithelial cells without nuclei; and metestrous by leukocytes and epithelial cells with translucent nuclei.

\section{Histology, immunofluorescence and in situ hybridization}

For each female mouse, one ovary was processed for immunofluorescence and the other one was subjected to quantitative RT-PCR. Tissues were fixed in $4 \%$ paraformaldehyde at $4{ }^{\circ} \mathrm{C}$ overnight and then embedded in OCT [39]. Cryosections (10 $\mathrm{mm})$ were processed for immunofluorescence, after rehydration. Sections were then incubated overnight at room temperature with primary antibodies at the indicated dilutions: rabbit antiCYP11A1 (1/200 dilution, gift of Dr Nadia Cherradi, CEA Grenoble) [40], rabbit anti-phospho-histone H3 (1/ 100 dilution, sc-8656, Santa Cruz Biotechnology, SantaCruz, CA, USA)), rat anti-H-Pgds (1/100 dilution, Cayman Chemical (SpiBio, France)), mouse anti- laminin (1/500 dilution, Sigma Aldrich), goat anti-FOXL2 (1/100 dilution, Santa Cruz Biotechnology) and goat anti-AMH (1/200 dilution, sc- 6886, Santa Cruz Biotechnology). After washing, sections were incubated with appropriate secondary antibodies (1/800 dilution, Alexa) (Molecular Probes, Invitrogen, Carlsbad, CA, USA) for $40 \mathrm{~min}$.

The antisense $H$-Pgds and FoxL2 RNA probes were PCR-amplified from embryonic mouse cDNAs, cloned in a pCRII Topo vector (Invitrogen) and sequenced using an ABI automatic sequencer. Digoxigenin-labeled riboprobes were synthesized using a digoxigenin RNA labeling kit, following the manufacturer's instructions (Roche Diagnostics, Indianapolis, IN, USA) and used for in situ hybridization experiments on cryosections of WT ovaries, as previously described $[20,41]$.

\section{RNA isolation and quantitative RT-PCR analysis of gene expression}

RNA isolation using the RNeasy Midi kit (Qiagen, Valencia, CA, USA) from frozen ovaries, reverse transcriptase and quantitative RT-PCR using a LightCycler480 apparatus (Roche Diagnostics) were carried out as previously described [20]. Gene expression levels were investigated using different pairs of primers (Table 1) and normalized to those of Gapdh or Hprt .

\section{Hormone and prostaglandin assays}

Hormone assays for estradiol and progesterone were performed from sera, by using ELISA kits (Cayman Chemicals, Progesterone EIA kit 582601 and Estradiol EIA kit 582251). Mice ( $n=20$ for WT and $n=20$ for HQL79-treated) at the estrous phase of their cycle, were anesthetized and blood was collected by cardiac puncture into plastic eppendorf tubes containing heparin. After centrifugation, the serum was extracted twice with methylene chloride; after evaporation, steroid extracts were stored at $-80^{\circ} \mathrm{C}$ until assays were performed. Determination of the hormone concentrations was performed in triplicate at two different dilutions according to the

Table 1 Sequences of oligonucleotides for real time PCR

\begin{tabular}{|c|c|c|c|}
\hline Primers & Sequence $5^{\prime}-3^{\prime}$ & Primers & Sequence $5^{\prime}-3^{\prime}$ \\
\hline mFSHRfwd & gtgcgggctactgctacact & mGapdhFwd & tggcaaagtggagattgttgcc \\
\hline mFSHRrev & caggcaatcttacggtctcg & mGapdhRev & aagatggtgatgggcttcccg \\
\hline mLHRqFwd & gatgcacagtggcaccttc & mP27Fwd & gagcagtgtccagggatgag \\
\hline mLHRqRev & cctgcaatttggtggaagag & mP27Rev & tctgttctgttggecctttt \\
\hline mStARqFwd & ttgggcatactcaacaacca & mCycD2Fwd & ctgtgcatttacaccgacaac \\
\hline mStARqRev & acttcgtccccgttctcc & mCycD2Rev & cactaccagttcccactccag \\
\hline mSCCqFwd & aagtatggccccatttacagg & mCox-1Fwd & cctctttccaggagctcaca \\
\hline msCCqRev & tggggtccacgatgtaaact & mCox-1Rev & tcgatgtcaccgtacagctc \\
\hline mDP1Fwd & cccagtcaggctcagactaca & $m C o x-2 F w d$ & gctcttccgagctgtgct \\
\hline mDP1Rev & aagtttaaaggctccatagtacgc & mCox-2Rev & cggttttgacatggattgg \\
\hline mDP2Fwd & catcgtggttgccttcgt & mPges-2Fwd & cccaggaaggagacagctt \\
\hline mDP2Rev & gcctccagcagactgaagat & mPges-2Rev & aggtaggtcttgagggcactaat \\
\hline mSF-1Fwd & cacgaaggtgcatggtctt & mHPgdsFwd & cacgctggatgacttcatgt \\
\hline mSF-1Rev & cagttctgcagcagtgtcatc & mHpgdsRev & aattcattgaacatccgctctt \\
\hline mCYP19Fwd & cctcgggctacgtggatg & mLPgdsFwd & ggctcctggacactacacct \\
\hline mCYP19Rev & gagagcttgccaggcgttaaa & mLPgdsRev & atagttggcctccaccactg \\
\hline mEP2Fwd & tgctccttgcctttcacaat & mFPFwd & ctggccataatgtgcgtct \\
\hline mEP2Rev & ctcggaggtcccacttttc & mFPRev & tgcaatgttggccattgtta \\
\hline hGapdhFwd & gagaaggctggggctcat & hHPgdsFwd & gagaatggcttattggtaactctgt \\
\hline hGapdhRev & tgctgatgatcttgaggctg & hHPgdsRev & aaagaccaaaagtgtggtactgc \\
\hline
\end{tabular}


kits'manufacturer. In each case, the twenty values were averaged.

PGD2, PGE2 and PGF2 $\alpha$ levels were determined using the PGD2 - MOX EIA Kit (Cayman Chemical 500151), PGE2 express EIA kit (500141, Cayman Chemical) and 13,14-dihydro-15keto PGF2 $\alpha$ (516671, Cayman Chemical), respectively. Ovaries were collected from mice treated $(n=8)$ or not $(n=8)$ by HQL-79 and immediately frozen on dry ice and then stored at $-80^{\circ} \mathrm{C}$. Ovaries were lyzed and proteins were extracted with cold acetone on ice and lyzates were evaporated under nitrogen flow. Prostaglandins were resuspended in $500 \mu \mathrm{l}$ EIA buffer and assayed as recommended by the kits supplier. Two dilutions (1 and 1/20) were assayed for prostaglandins content. The eight values for each group were averaged and statistical analysis was performed using Student's $t$ test, and results were considered statistically significant at a $P<0.05$.

\section{Statistical analysis}

Quantified real time RT-PCR signals were normalized to Gapdh or Hprt levels and the hormone levels of treated ovaries were compared to those of untreated ovaries. All values were presented as means \pm SE. Student's t test was used to determine the significance of differences in expression and hormone data. Results were considered significant at $\mathrm{P}<0.05$ for two-sided analysis.

\section{Results}

\section{$H$-Pgds and DP2 expression in adult mouse ovaries}

The mRNA for $H$-Pgds was detected by in situ hybridization in the growing follicles from the primary to the pre-ovulatory stage and in the corpus luteum. Figure 1A shows an expression of $\mathrm{H}-\mathrm{Pgds}$ mRNA in the granulosa cells of the developing follicles similar to that of the granulosa cell marker FoxL2 whereas hybridization with the control sense H-Pgds cRNA probe showed no significant signal (data not shown). In the antral and pre-ovulatory follicles, $\mathrm{H}$-Pgds expression is likely abolished in the external layers of mural granulosa cells, remaining only in the internal layers of granulosa cells and in granulosa cells forming the cumulus in the ovulatory follicle. $H$-Pgds mRNA was not detectable in the other ovarian cell types. In order to confirm H-Pgds expression in the granulosa cells at the protein level, we used immunofluorescence with (Figure 1B, arrows) or without (Figure $1 \mathrm{C}$, IgG control) a specific H-Pgds antibody. We then showed the DP2 receptor expression in the granulosa cells of primary, secondary, preantral (Figure 2A), antral (Figure 2B) and preovulatory (Figure 2C) follicles using an anti-rabbit DP2 antibody together with anti-FOXL2 (A) or anti-AMH (B, C) antibodies, two specific granulosa markers. Specific expression of DP2 in the granulosa cells was confirmed by high magnification imaging
(Figure 2D). However, DP1 receptor was not detected in any cell type at any stage (data not shown). Indeed, using real-time RT-PCR we observed significant levels of $D p 2$ transcripts (Figure $2 \mathrm{E}$ ), whereas $D p 1$ expression level remained undetectable in WT ovaries.

\section{Prostaglandin synthesis in the ovary upon inhibition of $\mathrm{H}$ - Pgds enzymatic activity}

We evaluated the implication of H-Pgds mediated-PGD2 signaling within the ovarian physiology using the H-Pgds specific inhibitor HQL-79 [36-38]. To confirm the significance of the inhibition by HQL-79 and evaluate the incidence of PGD2 depletion on prostaglandin production, we measured the level of PGD2, PGE2 and PGF2 $\alpha$ in ovaries of HQL-79-treated mice. As expected, the ovarian level of PGD2 was markely reduced by $65 \%$ in the HQL-79 treated mice compared to that in the untreated mice. However, no significant different levels of PGE2 and PGF2 $\alpha$ were measured (Figure 3A).

We then analyzed the PGD2 pathway components and showed by real time RT-PCR that H-Pgds expression was up-regulated concomitantly to the reduced level of PGD2 in HQL-79 treated ovaries (Figure 3B). On the other hand, no significantly different expression of the $D p 2$ and $P P A R \gamma$ genes (Figure $3 \mathrm{~B}$ ) was detected upon HQL-79 treatment and no expression of L-Pgds and Dp1 receptor genes was detected in the control or treated ovaries (data not shown).

To evaluate the impact of the PGD2 signaling on other prostaglandin pathways and considering the importance of PGE2 and PGF $2 \alpha$ for ovarian function, we then determined the mRNA contents of cyclooxygenases Cox 1 and Cox2, prostaglandin synthase (membrane-bound) m-Pges-2, and the receptors Ep2 and Fp by quantitative RT-PCR in ovaries from mice (in estrous phase) treated with vehicle or HQL-79. The ovarian Cox1, Pges and Ep2, Fp mRNA levels were not significantly different in the untreated or HQL-79 treated mice (Figure $3 \mathrm{C}$ ) that were in agreement with the stable levels of PGE2 and PGF2 $\alpha$. However, the expression of Cox-2 was significantly increased by 10 fold in HQL-79 treated ovaries compared to control ovaries (Figure 3C).

Taken together, these results indicate that $65 \%$ of $\mathrm{H}$ Pgds activity were inhibited by HQL-79 but this treatment has no effect on PGE2 and PGF2 $\alpha$ prostaglandin pathways in the ovary; however, the reduced level of PGD2 induces Cox-2 gene expression that could contribute to the up-regulation of $\mathrm{H}-\mathrm{Pg} d s$ gene expression in order to restore the intraovarian PGD2 content.

\section{PGD2 signaling is necessary for FSH signaling and steroidogenesis in the mouse ovary}

Folliculogenesis and synthesis of steroid hormones in the ovary depends on the coordinated actions of FSH 

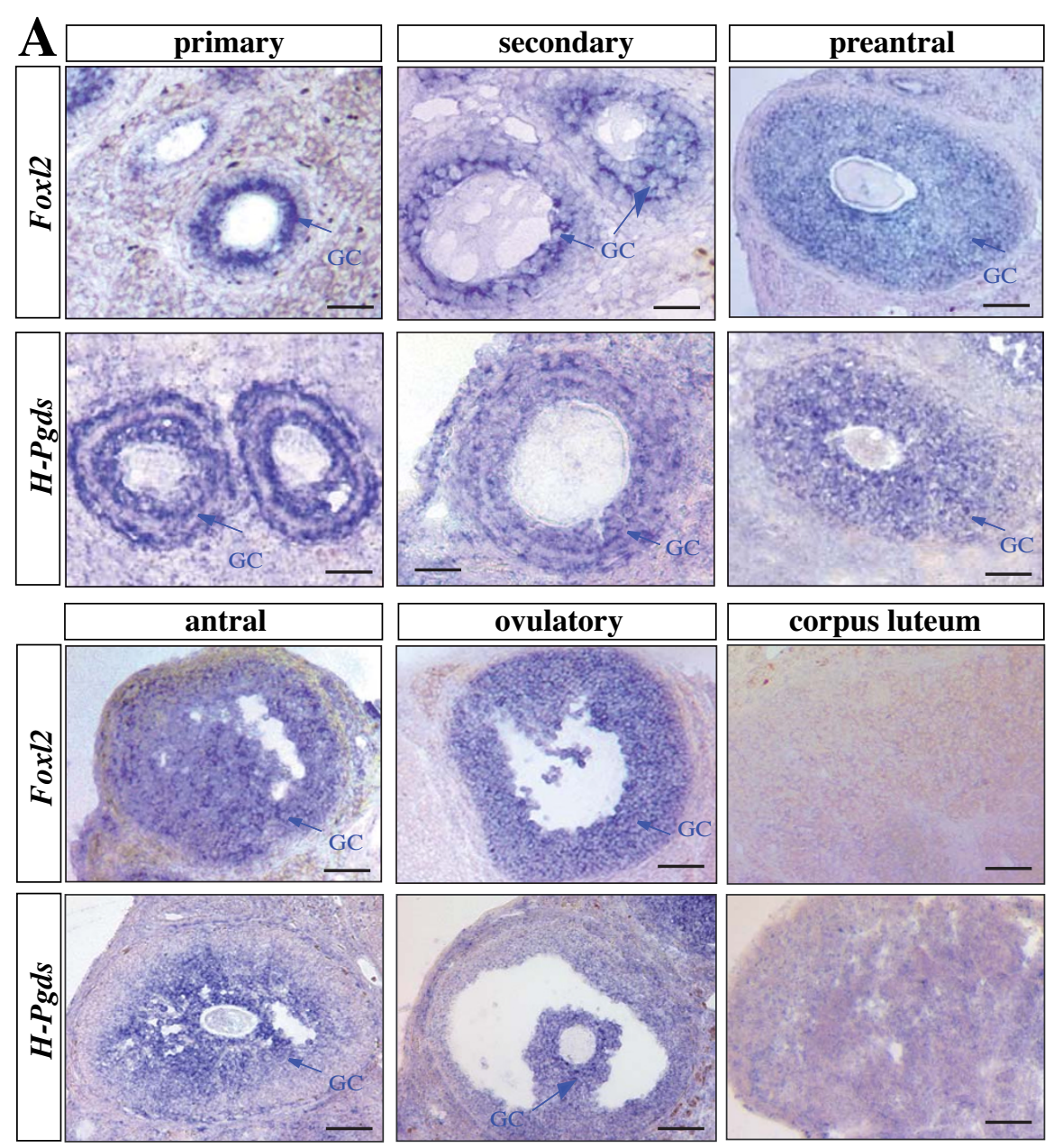

B
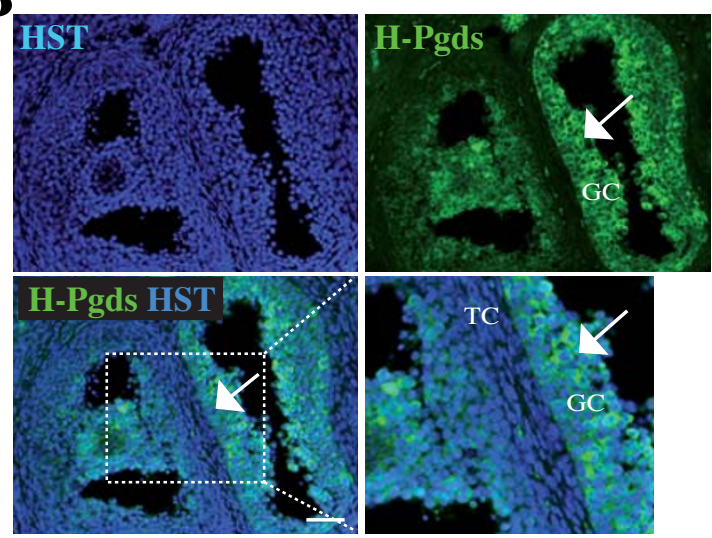

C
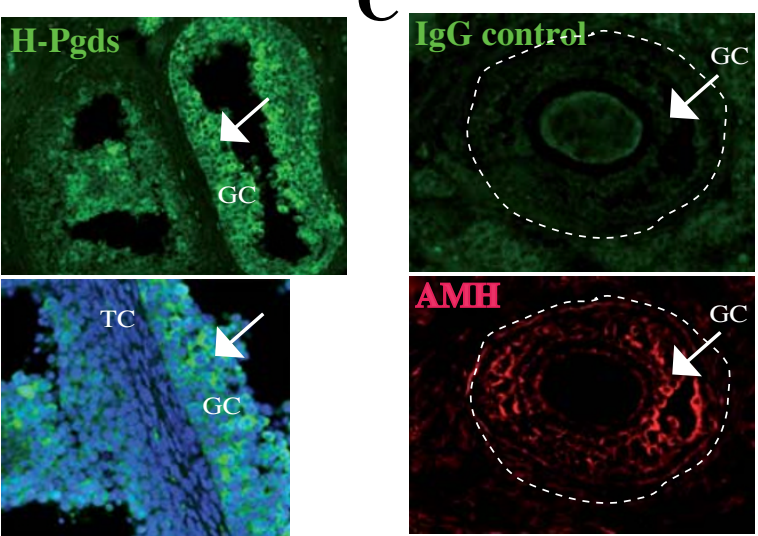

Figure 1 Expression of H-Pgds in the mouse adult ovary. (A), In situ hybridization for H-Pgds and granulosa cell marker FoxL2 was performed on sections from wild type adult ovaries. Primary, secondary, pre-antral, antral, ovulatory follicles and corpus luteum are represented for $\mathrm{H}$-Pgds and FoxL2 mRNA expression and expressing granulosa cells (GC) are labeled by a blue arrow. Scale bars = 50 Hm. (B), H-Pgds protein expression was detected in granulosa cells on wild type adult ovary sections, using an anti-H-Pgds antibody (in green) whereas nuclei are labeled in blue by the Hoescht Dye (HST). The merge panel has been enlarged on the right bottom panel. Arrows indicate H-Pgds expressing granulosa cells. TC, theca cells; GC, granulosa cells. Scale bar $=50 \mu \mathrm{m}$. (C), Control immunofluorescence experiment with no primary H-Pgds antibody (IgG control) showing the specificity of the antibody. AMH staining in granulosa cells was used on the same slide. Arrows indicate granulosa cells (GC). 


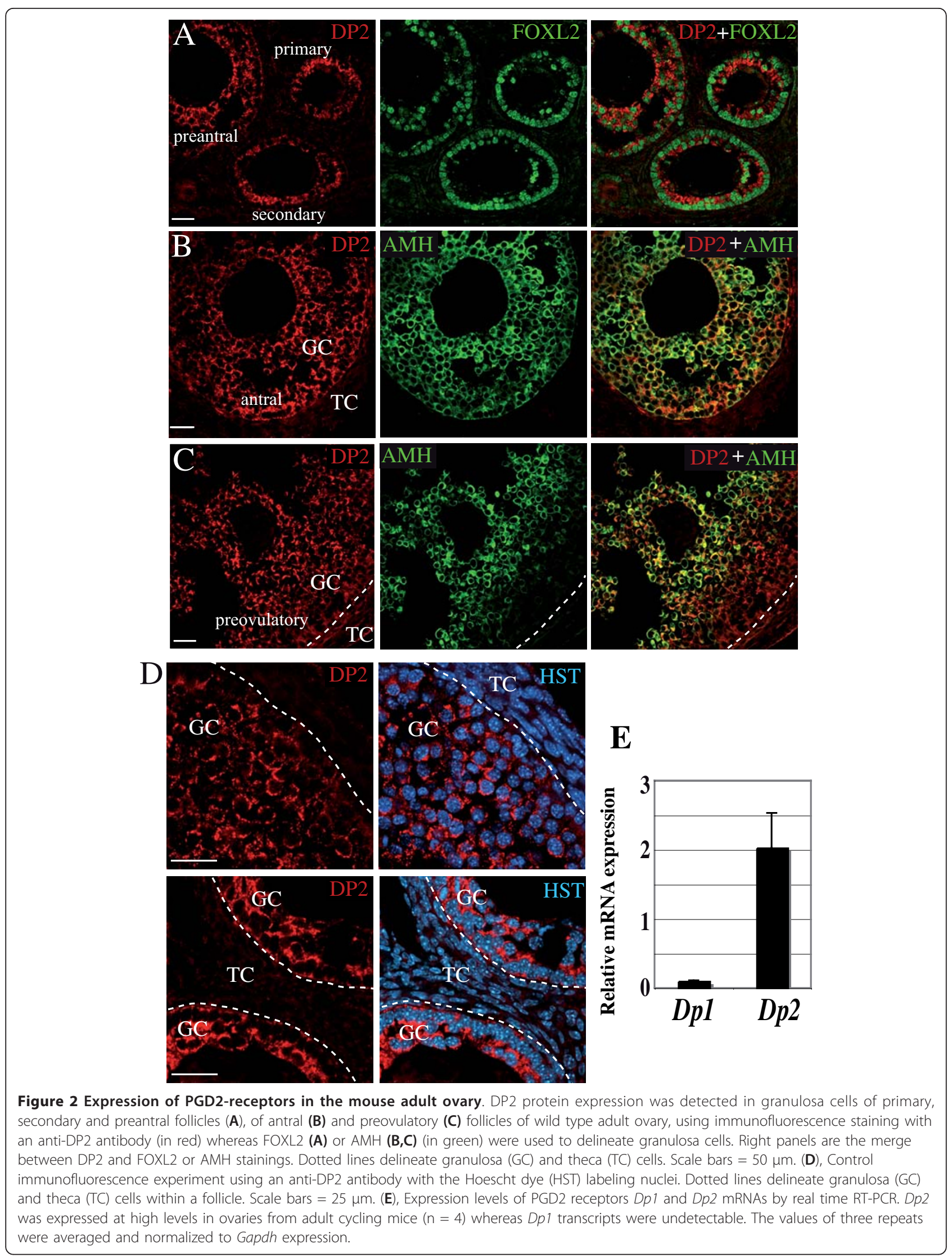


A

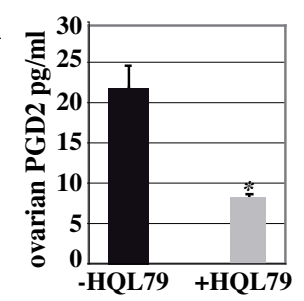

B
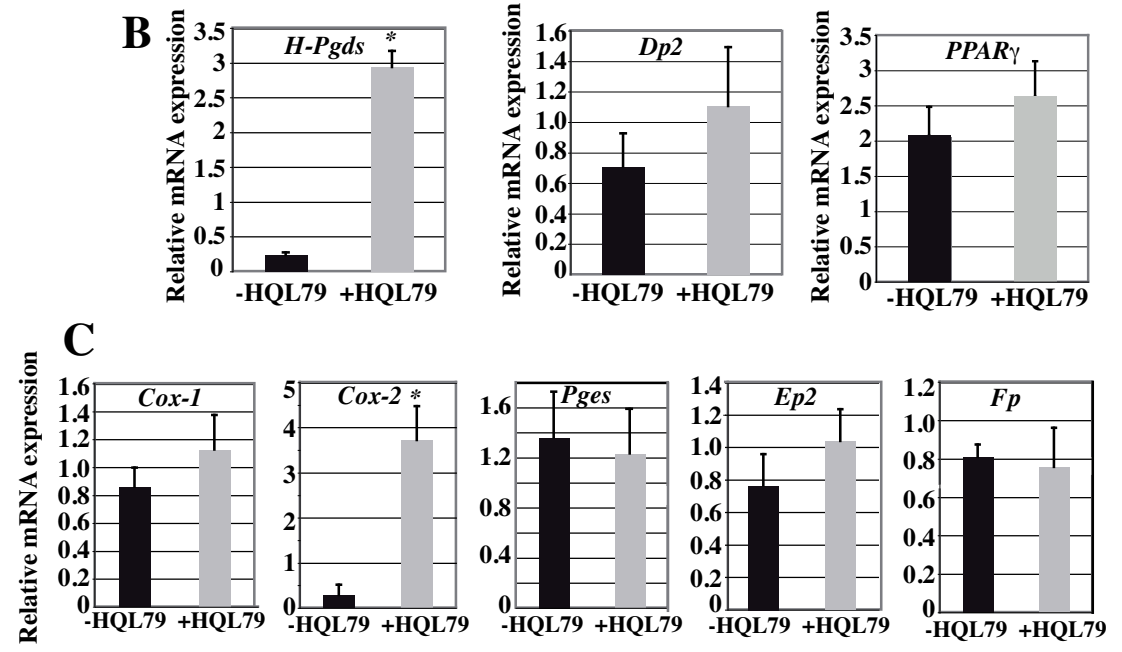
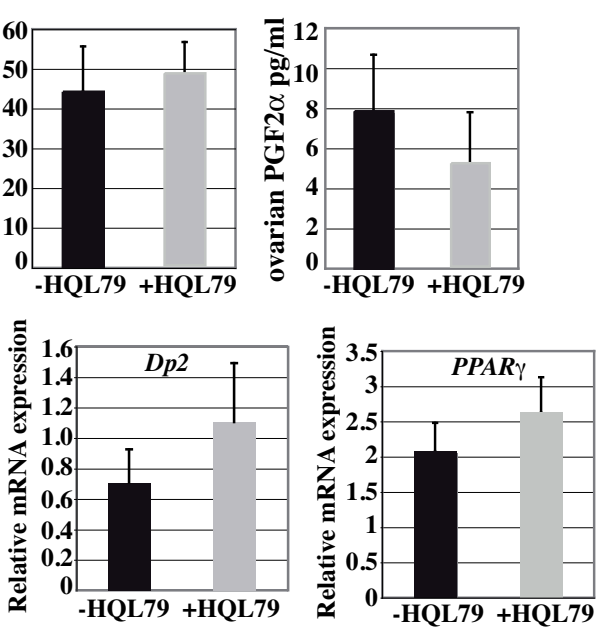

Figure 3 Prostaglandins synthesis in the ovary upon PGD2 depletion. (A), Levels of PGD2, PGE2 and PGF2 $\alpha$ were measured using ELISA in HQL-79 treated or not ovaries ( $n=8$ for each condition). Results expressed in pg of prostaglandin/ml showed that PGD2 content is significantly decreased (P-value < 0.01) by 65\% upon HQL-79 treatment whereas PGE2 and PGF2 $\alpha$ contents were not affected; error bars indicate SD of assays done with two dilutions of the eight samples of each group. Expression levels of H-Pgds, Dp2, PPAR $(\mathbf{B})$ and Cox-1, Cox-2, mPges-2, Ep2, $F p(\mathbf{C})$ in ovaries of HQL-79 treated $(n=8)$ or not $(n=8)$ mice. By real time RT-PCR, no significant difference of Dp2, PPAR $\boldsymbol{\gamma}(\mathbf{B})$ and Cox-1, mPges-2, Ep2, Fp (C) expression level was detectable whereas a large increase of Cox-2 and $\mathrm{H}$-Pgds expression level was measured upon $\mathrm{HQL}-79$ treatment. All the expression level values were normalized to those of Hprt. Data are expressed as means $+/-$ SE (columns and bars); * $\mathrm{P}<0.05$ vs control.

and $\mathrm{LH}$ acting through their respective receptors FshR and LhR [2]. We thus evaluated the implication of $\mathrm{H}$ Pgds mediated-PGD2 signaling within the gonadotropin pathways. Adult female mice were treated with the $\mathrm{H}$ Pgds inhibitor HQL-79 (at doses $0.1-1$ or $10 \mathrm{mg} / \mathrm{kg} /$ day) [36-38] or with vehicle for five to nine days until mice reached the estrous phase and the resulting ovaries were examined in terms of their expression of gonadotropin receptors and ovarian markers. For the three doses of HQL-79, the reduced level of H-Pgds produced PGD2 clearly impaired ovarian gonadotropin receptor expression, as shown by the reduction in FshR and $L h R$ levels by $50 \%$ and $80 \%$ respectively (data not shown for 0.1 and $10 \mathrm{mg} / \mathrm{kg} /$ day and Figure $4 \mathrm{~A}$, dose $1 \mathrm{mg} / \mathrm{kg} /$ day). Induced steroidogenesis is regulated by increased StAR (steroidogenic acute regulatory) protein expression under the positive control of gonadotropin signaling. StAR is the primary regulator of cholesterol transport into the mitochondria where the steroid precursor is then converted by CYP11A1 side-chain cleavage enzyme (P450scc) to pregnenolone. We demonstrated here that, when compared to levels in the untreated ovary, inhibition of H-Pgds enzymatic activity significantly reduced expression of StAR and Cyp11A1 genes by $60 \%$ and $50 \%$ respectively (Figure 4B), whereas PGD2 signaling did not affect expression levels of SF-1, a major activator of steroidogenesis gene expression. In contrast, expression levels of the Cyp19A1 gene increased significantly by $30 \%$ (Figure 4B). CYP11A1 protein expression was also largely reduced in granulosa cells of the growing follicles of ovaries treated by HQL-79, when compared to that observed in WT ovaries (Figure 4C).

We next evaluated serum levels of the ovarian steroid hormones estradiol and progesterone in twenty WT and twenty female mice treated with HQL-79 for five to nine days, all in the estrous period. The results showed a significant reduction of $50 \%$ in the basal level of progesterone in the mice treated with HQL-79, when compared to that measured in the WT (Figure 5A). In contrast, the estradiol level increased by $50 \%$ in the HQL-79 treated mice compared to WT (Figure 5B), following the increased aromatase Cyp19A1 expression described above (Figure 4B). 

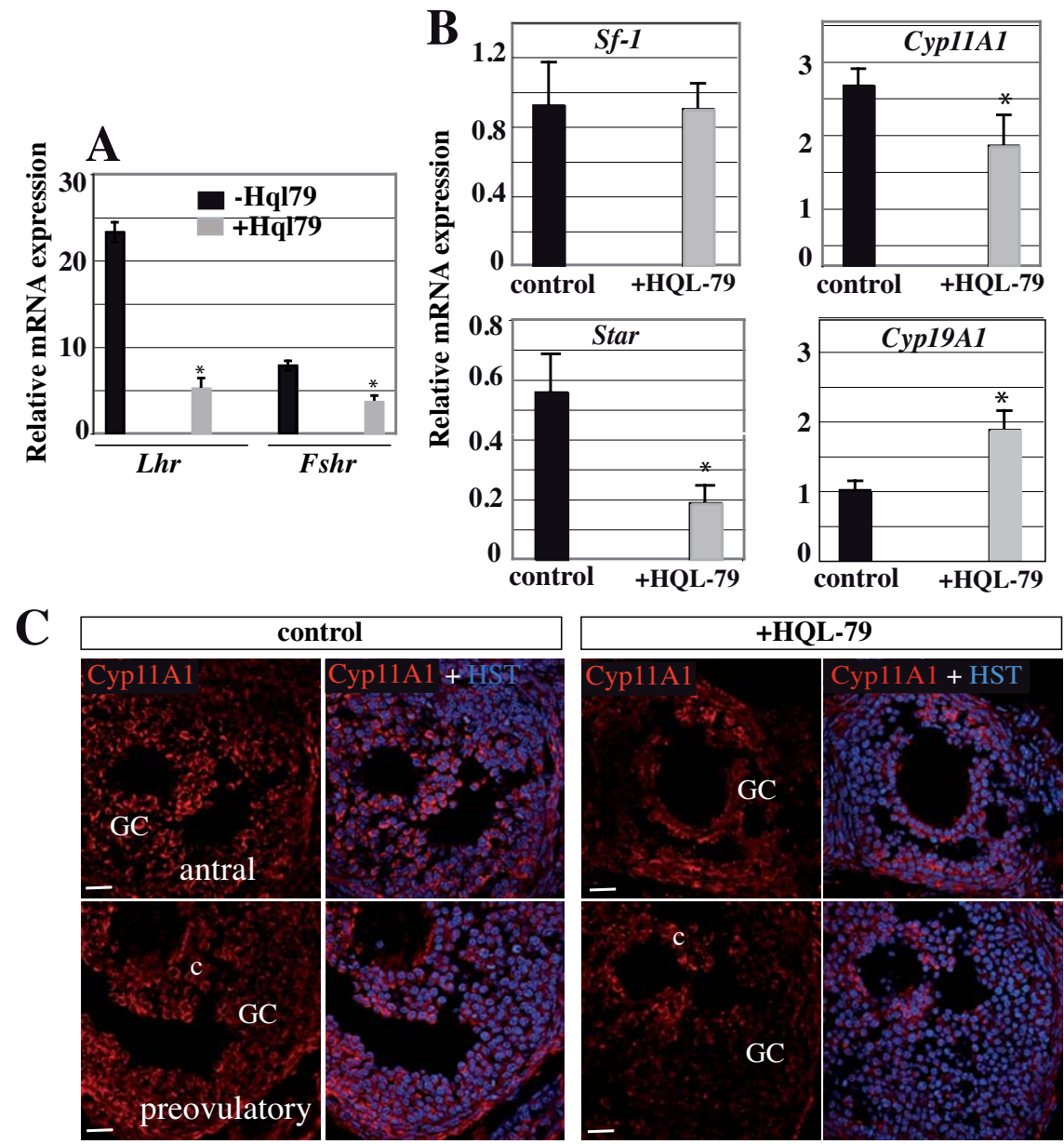

Figure 4 PGD2 signaling regulates gonadotropin receptors and steroidogenic genes expression. FshR and LhR (A) and Sf-1, Cyp11A1, StAR, Cyp19A1 (B) mRNA expression levels were assessed using real time RT-PCR in ovaries from adult cycling mice treated $(n=10)$ or not $(n=$ 10) using H-Pgds inhibitor HQL-79 (1 mg/kg/day). The values of at least two repeats of two different RT reactions were averaged and normalized to Gapdh expression. Values represent mean +/- SEM and * represents significant differences $P<0.025$ compared with untreated ovaries (control). (C), CYP11A1 protein expression was detected in untreated (control) or treated (+HQL-79) ovaries (in red). Upon HQL-79 treatment, a largely decreased expression is detected in antral and preovulatory follicles. Nuclei are labeled in blue (Hoescht dye, HST). GC: granulosa cells, c: cumulus cells. Scale bars $=50 \mu \mathrm{m}$.

To evaluate the relationships between PGD2 signaling and FSH action, we stimulated mice with PMSG which mimics the function of FSH. As expected, FshR and $L h R$ expression was increased by 2.5 fold in PMSG-treated versus untreated control ovaries (Figure 6A). Accordingly, this stimulation was inhibited upon co-treatment with the HQL-79 inhibitor (Figure 6A), indicating the requirement for intact PGD2 signaling in order for PSMG to take effect. Subsequently, inhibition of H-Pgds activity also inhibited StAR expression induced after PMSG treatment (Figure 6D) whereas Cyp11A1 expression decreased after HQL-79 treatment (Figure 6C), confirming that PGD2 is involved in Cyp11A1 activation. On the other hand, $S F-1$ expression level remained independent of PMSG and HQL-79 treatment (Figure 6B).
H-Pgds-produced PGD2 is implicated in the control of granulosa cell proliferation

We assessed the length of estrous cycles in five WT and five HQL-79-treated adult mice using vaginal smears collected over 16 consecutive days (three to four cycles). The WT mice (-HQL-79) had cyclical estrous cycles lasting more than five days (5.3 days) whereas in contrast, HQL-79 treated (+HQL-79) mice had significantly shorter cycles lasting less than four days (3.8 days) (Figure 7A, P-value: 0.0097). To characterize the observed changes of inactivation of $\mathrm{H}$-Pgds activity at the cellular level, we examined the proliferation rate of granulosa cells (GCs) in the developing follicles. GCs partially depleted of PGD2 signaling showed an increased proliferation upon immunostaining for mitosis marker 


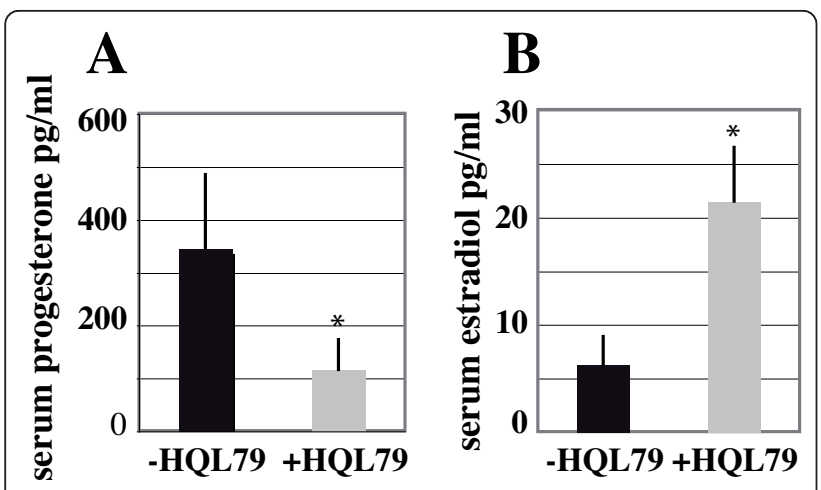

Figure 5 Progesterone and estradiol production is modified upon $\mathrm{H}$-Pgds enzymatic inhibition. (A), serum progesterone

levels. (B), serum estradiol levels were measured by Elisa on extracted sera. Bars represent the average of twenty animals ( $n=20$ for untreated mice and $n=20$ for HQL-79 treated mice). HQL-79 treatment induces a 50\% decrease of progesterone production and a $50 \%$ increase of estradiol production. * represents significant differences $P<0.05$, compared to untreated ovaries (-HQL-79).

phosphohistone H3 (phosphoH3) (Figure 7B). A significant increase of $30 \%$ in granulosa cell proliferation was seen in the pre-antral follicles and reached $50 \%$ in the GCs of antral follicles of HQL-79 treated ovaries, compared to untreated ovaries (Figure 7C). In contrast, apoptosis in the GCs of the growing follicles was not modified by the lack of PGD2 signaling (data not shown). As shown in Figure 7D, this increase in cell proliferation is associated with a significantly decreased expression of $C D K N 1 B$ (p27) in the treated ovaries, whereas levels of CyclinD2 expression remained unmodified. Consequently, the number of corpora lutea in HQL-79 ovaries was increased by two fold compared to that in untreated ovaries (Figure 7E) (female mice at the proestrous phase of their cycle), suggesting that upon HQL-79 treatment, the number of growing and maturating follicles have increased. Collectively, these results support the hypothesis where PGD2 signaling negatively impacts GC proliferation in vivo, thus promoting conditions favoring granulosa cell differentiation and subsequently steroidogenesis.

\section{Discussion}

In this study, we describe the expression of $H$-Pgds mRNA in the adult mouse ovary. This localization includes granulosa cells from growing follicles through primary to antral and pre-ovulatory stages, and the corpus luteum formed after ovulation. H-Pgds is thus the sole source of PGD2 in the ovary since the second enzyme able to produce PGD2 (L-Pgds) is not expressed [19]. In the embryonic gonad, LPgds secreted PGD2 signals through the adenylcyclasecoupled receptor DP1 to activate expression of the Sertoli cell differentiating gene Sox 9 and contribute to the nuclear

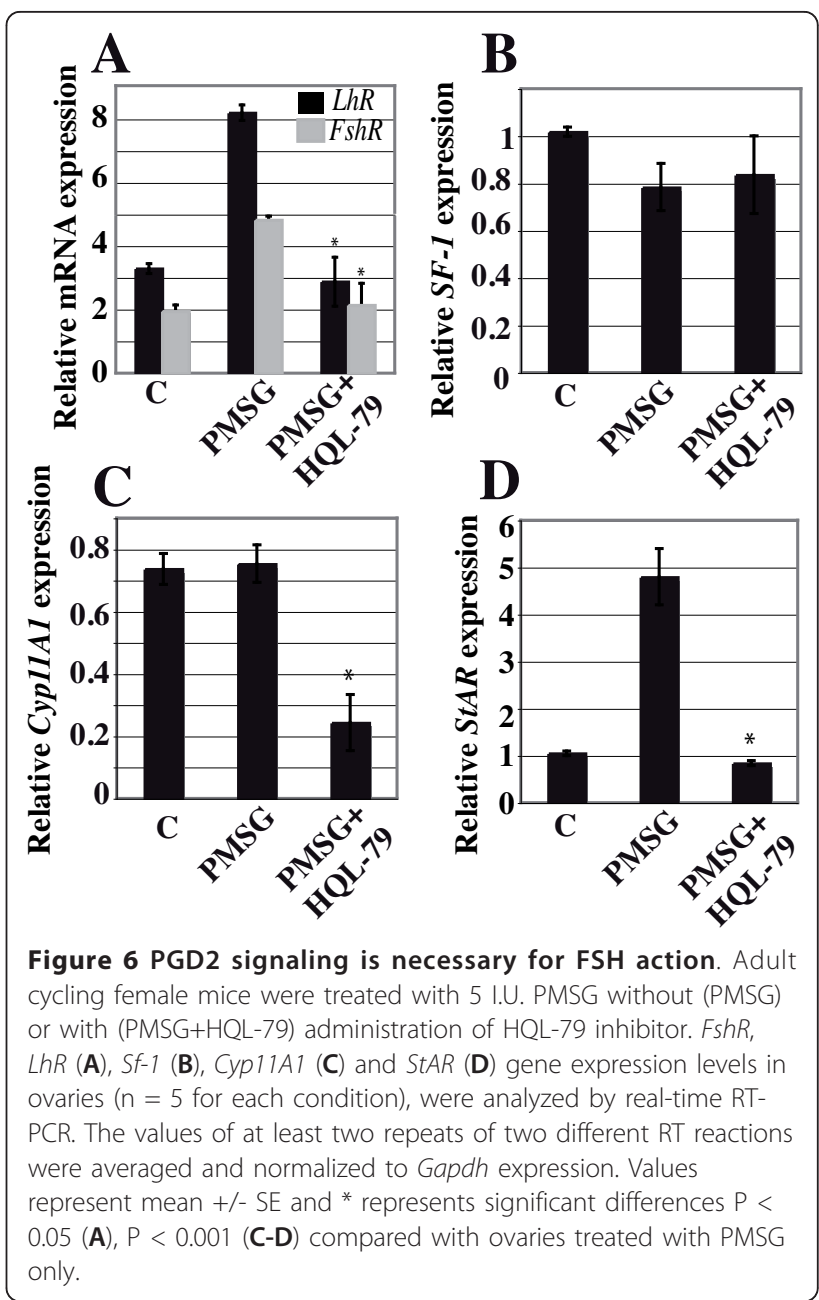

translocation of SOX9 protein [19,30]. In the adult ovary, the $\mathrm{Ca}^{++}$coupled DP2 receptor is exclusively expressed in granulosa cells. Considering how Sertoli and granulosa cells have common ancestor precursor cells [42], this differential expression of both receptors and the dual functional convergence between L- and H-Pgds might constitute part of the antagonistic regulation between male and female pathways $[43,44]$ and be a key regulatory step in maintaining the differentiation of both Sertoli and granulosa cell types [45]. PGD2 is metabolized to $15 \mathrm{~d}$ PGJ2, the high affinity natural ligand for the PPAR $\gamma$ receptor expressed in granulosa cells of developing follicles $[46,47]$. These results thus suggest that both receptors DP2 and PPAR $\gamma$ might relay PGD2 signaling in the adult ovary.

The process of granulosa cell differentiation occurring throughout progression from a pre-antral to pre-ovulatory follicle is dependent on sufficient FSH stimulation $[48,49]$ and is marked by the acquisition of $F s h R$ and $L h R$ expression and increased steroidogenesis. In this study, we demonstrated that H-Pgds enzymatic activity 

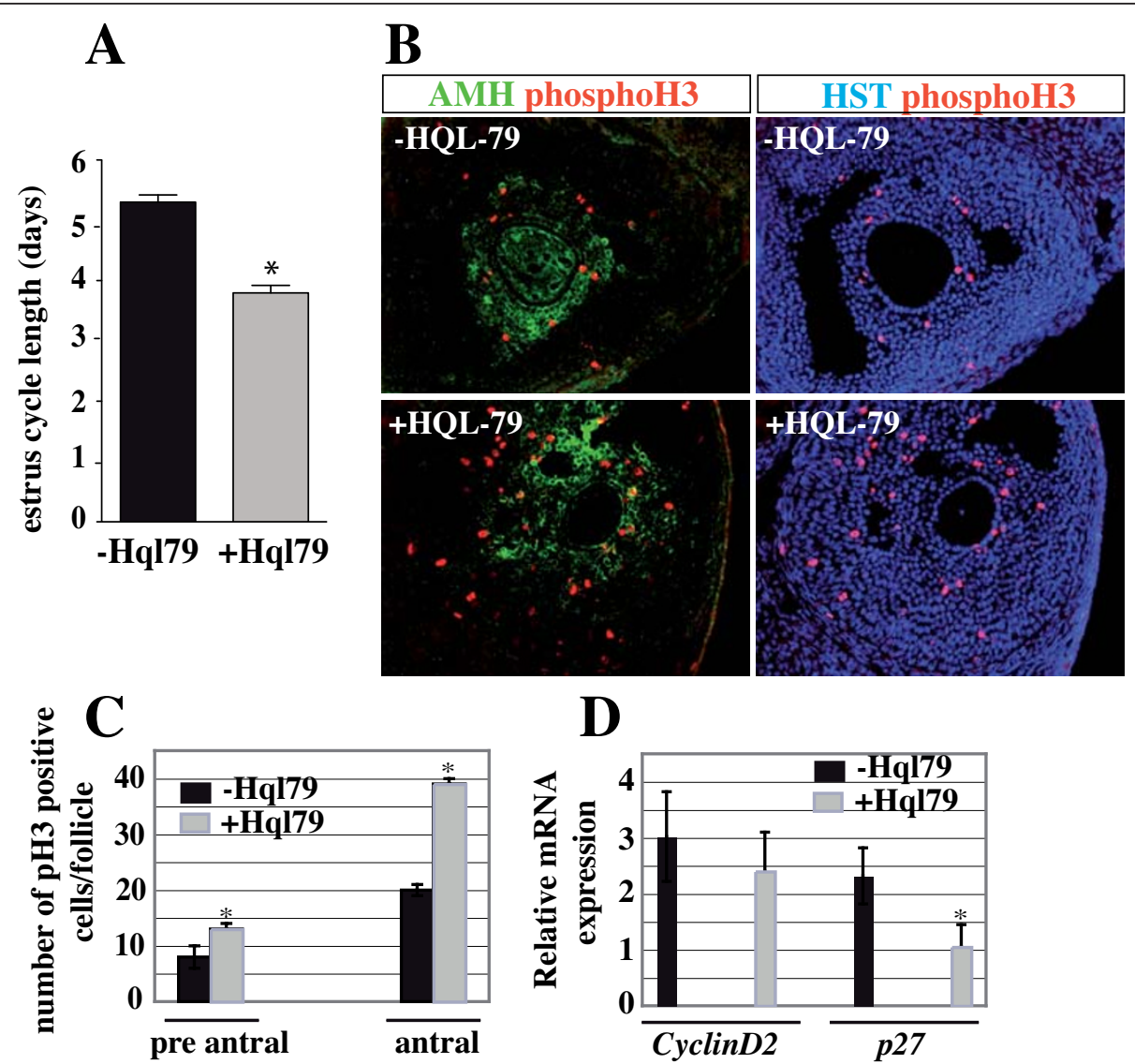

$\mathbf{E}$

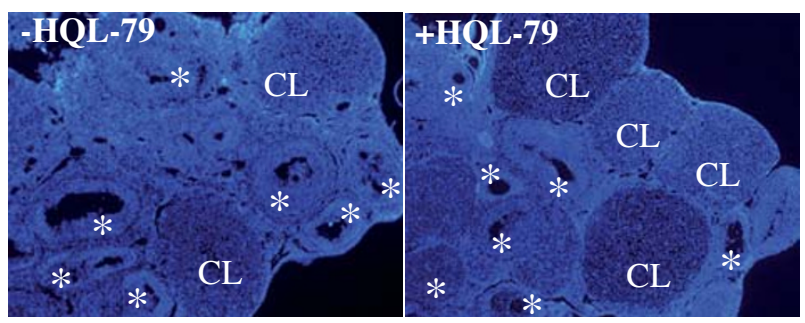

Figure 7 PGD2 signaling controls the granulosa cell proliferation. (A), The length of estrous cycles in five WT and five HQL-79-treated adult mice were assessed in vaginal smears collected every day for 16 consecutive days. Results of the five animals were averaged and were expressed as means $+/$ - SE (colums and bars), * P value $=0.0097$. (B), Proliferation of granulosa cells of antral follicles was assessed using immunofluorescence with mitosis marker phosphohistone $\mathrm{H3}$ (phosphoH3) antibody (in red) on cryosections of wild type (-HQL-79) or HQL-79 (+HQL-79) treated ovaries; granulosa cells were identified by anti-Müllerian hormone (AMH) antibody (in green) and nuclei were labeled by the Hoescht Dye (HST) (in blue). Numbers of phospho-H3-positive cells were determined on ten independent fields of three different ovaries for each condition and are represented on the graphs $(\mathbf{C}) .{ }^{*}$ represents significant increased number of mitotic cells in HQL-79 treated compared to that in untreated ovaries. (D), CyclinD2 and p27 expression levels in five wild type and five HQL-79-treated ovaries were quantified by real time RT-PCR and were normalized to Gapdh expression. Values are the result of averaged experiments (done in triplicate) on the five independent ovaries. * represents the significant decrease of p27 expression in HQL-79 compared to that in untreated ovaries (P-value $<0.025)$. (E), The follicular content of HQL-79 treated ovaries (at their proestrous stage) were compared to that of WT ovaries by labeling sections with the Hoescht dye. CL: corpora lutea, * growing follicles.

is required in order for FSH to regulate expression of both FshR and $L h R$ receptors, suggesting PGD2 to be an autocrine positive regulator of $F s h$ and $L h R$ expression in the ovary. This regulation may act directly on the FSH-induced FshR promoter activity as in the case of
inhibin-A [50], or might otherwise act indirectly by increasing FshR mRNA stability, as in the case of IGF-I [51]. The inhibition of H-Pgds enzymatic activity leads to a decrease in FshR and $L h R$ expression but does not affect that of $S F-1$, the major activator of steroidogenesis 
gene expression [52]. This supports the implication of PGD2 signaling in the FSH-induced expression of the StAR gene, independently on SF-1. SF-1 is essential for the development and function of the reproductive axis at multiple levels [52] and FSH has been shown to activate SF-1-mediated transcription using various mechanisms [53]. Thus, regulation of $F s h R$ expression might be one of the causes of $L h R$ and steroidogenic gene downregulation, and of the decrease in progesterone production upon PGD2 signaling inhibition [54].

In contrast, following the decrease in Cyp11A1 and StAR expression levels upon PGD2 depletion, we found that levels of both aromatase expression and serum estradiol increased in treated female mice compared to untreated animals. On the other hand, we observed that granulosa cells partially depleted of PGD2 signaling show increased proliferation based on immunostaining for mitosis marker phosphohistone $\mathrm{H} 3$, which we confirmed at the molecular level through the significantly decreased expression of CDKN1B (p27). This increased proliferation lead to an increased number of the maturating follicles that might explain the higher levels of Cyp19A1 mRNA expression and secreted estradiol upon HQL-79 treatment, rather than being a consequence of the Cox-2 up-regulation that was detected in HQL-79 ovaries. The up-regulation of Cyp19A1 gene expression via COX-2 was shown to be dependent on PGE2 synthesis and cAMP signaling in undifferentiated rat granulosa cells [9] or in human breast tumor cells [55]. Our data showed that Cox-2 expression is up-regulated, however, PGE2 synthesis was not modified. Indeed, the sideeffect of HQL-79 treatment (i.e. increased PGE2 production) [26] related in the lung tissues of sensitized guinea pigs [56] was not detected in our system as it has not been seen in sheep vesicular gland microsomes [56] or in vivo in $\mathrm{H}-\mathrm{Pgds}$ transgenic mouse strain [36].

In this study, we measured high levels of $C o x-2$ and $\mathrm{H}-\mathrm{Pgds}$ transcripts whereas no modification of Cox-1 has been measured in HQL-79 treated ovaries. The functional coupling between H-Pgds/Cox-1 or H-Pgds/ Cox-2 has been demonstrated respectively, in the immediate or the delayed response in mast cells during the cytokine stimulation [38], even though tightly coupling between H-Pgds and Cox-1 is preferentially documented [36,57]. The up-regulation of Cox-2 associated with the down-regulation of $\mathrm{H}$-Pgds protein expression upon HQL-79 treatment has been previously described in the mouse ischemic brain [58]. In the ovary, we can assume that partial depletion of PGD2 might induce Cox-2 gene expression that in turn, might activate $\mathrm{H}-$ Pgds expression in order to restore the intraovarian PGD2 content. PGJ2, a PGD2 metabolite was shown to inhibit osteoblastic differentiation through PPAR $\gamma$ activation and down-regulation of Cox-2 [59]. This process would take place without any interaction with other prostanoid-synthetizing mechanisms as it has been previously reported in other systems, induction of fever [60] or induction of inflammation in muscle necrosis [61], since PGE2 and PGF2 $\alpha$ prostaglandin pathways are not modified upon HQL-79 treatment.

Using the H-Pgds specific inhibitor HQL-79 known to exactly mimic the phenotype of $\mathrm{H}$-Pgds $\mathrm{KO}$ mice in various systems such as inflammation, muscle necrosis $[31,38]$, we identify an important and unappreciated role for PGD2 signaling in modulating the balance of proliferation, differentiation and steroidogenic activity of the granulosa cells, through both FSH dependent and independent mechanisms. Thus, these results suggest PGD2 as a modulator of follicle development, even though no reproductive defects have been reported in female $\mathrm{H}$-Pgds $\mathrm{KO}$ mice $[31,62]$. The physiological importance of PGD2 for ovarian function and normal female fertility might be assessed in this mouse strain or in mice conditionnally invalidated for H-Pgds in the ovary under the control of Anti-Müllerian hormone (Amh) promoter (Amh-cre, [63]) to overcome a putative central effect of H-Pgds produced PGD2.

\section{Abbreviations}

FSH: follicle-stimulating hormone; LH: luteinizing hormone; Cox-2: cyclooxygenase-2; CYP11A1: cytochrome P450 11A1 (P450scc: Cholesterolside chain cleavage enzyme); CYP19A1: cytochrome P450 19A1 (aromatase); StAR: steroidogenic acute regulatory protein; SF-1: steroidogenic factor 1; PGD2: prostaglandin D2; PGE2: prostaglandin E2; PGF2a: prostaglandin F2a; PPARY: peroxisome proliferator-activated receptor gamma; PMSG: pregnant mare serum gonadotropin

\section{Acknowledgements}

The authors thank Brigitte Moniot for her help with in situ hybridization experiments. We thank Dr Julien Cau for assistance in confocal imagery (Imagery platform MRI/IGH); we also thank Florence Arnal and Elodie Gavois from the IGH animal care facility for providing mice and for helpful discussions. A. F. was supported by a PhD fellowship from the "Ligue Nationale contre le Cancer ». The work was supported by the CNRS and by the Ligue Régionale contre le Cancer (B.B.B.).

\section{Author details}

'Institut de Génétique Humaine, Department of Genetic and Development, CNRS UPR1142, 141, rue de la Cardonille, 34396 Montpellier CEDEX5, France. ${ }^{2}$ Service d'Hormonologie, Hôpital Lapeyronie, CHU Montpellier, France.

\section{Authors' contributions}

All authors read and approved the final manuscript. Conceived and designed the experiments: FP, BBB. Performed the experiments: AF, PP, FP, BBB. Analyzed the data: AF, PP, CS, FP, BBB. Contributed reagents/materials/ analysis tools: $\mathrm{CS}, \mathrm{FP}, \mathrm{BBB}$. Wrote the paper: BBB.

\section{Competing interests}

The authors declare that they have no competing interests.

Received: 21 December 2010 Accepted: 25 February 2011 Published: 25 February 2011

\section{References}

1. Richards JS, Fitzpatrick SL, Clemens JW, Morris JK, Alliston T, et al: Ovarian cell differentiation: a cascade of multiple hormones, cellular signals, and regulated genes. Recent Prog Horm Res 1995, 50:223-254. 
2. Fortune JE: The early stages of follicular development: activation of primordial follicles and growth of preantral follicles. Anim Reprod Sci 2003, 78:135-163.

3. Challis JR: Prostaglandins and reproduction-what do knockouts really tell us? Nat Med 1997, 3:1326-1327.

4. Cha YI, Solnica-Krezel L, DuBois RN: Fishing for prostanoids: deciphering the developmental functions of cyclooxygenase-derived prostaglandins. Dev Biol 2006, 289:263-272.

5. Lim H, Paria BC, Das SK, Dinchuk JE, Langenbach R, et al: Multiple female reproductive failures in cyclooxygenase 2-deficient mice. Cell 1997, 91:197-208.

6. Kennedy CR, Zhang Y, Brandon S, Guan Y, Coffee K, et al: Salt-sensitive hypertension and reduced fertility in mice lacking the prostaglandin EP2 receptor. Nat Med 1999, 5:217-220.

7. Sirois J, Richards JS: Purification and characterization of a novel, distinct isoform of prostaglandin endoperoxide synthase induced by human chorionic gonadotropin in granulosa cells of rat preovulatory follicles. $J$ Biol Chem 1992, 267:6382-6388

8. Hizaki H, Segi E, Sugimoto Y, Hirose M, Saji T, et al: Abortive expansion of the cumulus and impaired fertility in mice lacking the prostaglandin E receptor subtype EP(2). Proc Natl Acad Sci USA 1999, 96:10501-10506.

9. Cai Z, Kwintkiewicz J, Young ME, Stocco C: Prostaglandin E2 increases cyp19 expression in rat granulosa cells: implication of GATA-4. Mol Cell Endocrinol 2007, 263:181-189.

10. Arosh JA, Banu SK, Chapdelaine P, Madore E, Sirois J, et al: Prostaglandin biosynthesis, transport, and signaling in corpus luteum: a basis for autoregulation of luteal function. Endocrinology 2004, 145:2551-2560.

11. Challis JR, Calder AA, Dilley S, Forster CS, Hillier K, et al: Production of prostaglandins $\mathrm{E}$ and Falpha by corpora lutea, corpora albicantes and stroma from the human ovary. J Endocrinol 1976, 68:401-408.

12. Sugimoto Y, Yamasaki A, Segi E, Tsuboi K, Aze Y, et al: Failure of parturition in mice lacking the prostaglandin F receptor. Science 1997, 277:681-683.

13. Challis JR, Lye SJ, Gibb W: Prostaglandins and parturition. Ann N Y Acad Sci 1997, 828:254-267.

14. Challis JR, Sloboda DM, Alfaidy N, Lye SJ, Gibb W, et al: Prostaglandins and mechanisms of preterm birth. Reproduction 2002, 124:1-17.

15. Weems CW, Weems YS, Randel RD: Prostaglandins and reproduction in female farm animals. Vet J 2006, 171:206-228.

16. Fortune JE, Willis EL, Bridges PJ, Yang CS: The periovulatory period in cattle: progesterone, prostaglandins, oxytocin and ADAMTS proteases. Anim Reprod 2009, 6:60-71.

17. Breyer RM, Bagdassarian CK, Myers SA, Breyer MD: Prostanoid receptors: subtypes and signaling. Annu Rev Pharmacol Toxicol 2001, 41:661-690.

18. Matsuoka T, Hirata M, Tanaka H, Takahashi Y, Murata T, et al: Prostaglandin D2 as a mediator of allergic asthma. Science 2000, 287:2013-2017.

19. Malki $S$, Nef $S$, Notarnicola C, Thevenet $L$, Gasca $S$, et al: Prostaglandin D2 induces nuclear import of the sex-determining factor SOX9 via its CAMPPKA phosphorylation. Embo 2005, J 24:1798-1809.

20. Moniot B, Declosmenil F, Barrionuevo F, Scherer G, Aritake $K$, et al: The PGD2 pathway, independently of FGF9, amplifies SOX9 activity in Sertoli cells during male sexual differentiation. Development 2009, 136:1813-1821.

21. Boie Y, Sawyer N, Slipetz DM, Metters KM, Abramovitz M: Molecular cloning and characterization of the human prostanoid DP receptor. J Biol Chem 1995, 270:18910-18916.

22. Breyer MD, Breyer RM: $G$ protein-coupled prostanoid receptors and the kidney. Annu Rev Physiol 2001, 63:579-605.

23. Toth B, Hornung D, Scholz C, Djalali S, Friese K, et al: Peroxisome proliferator-activated receptors: new players in the field of reproduction. Am J Reprod Immunol 2007, 58:289-310.

24. Urade $\mathrm{Y}$, Eguchi N: Lipocalin-type and hematopoietic prostaglandin $\mathrm{D}$ synthases as a novel example of functional convergence. Prostaglandins Other Lipid Mediat 2002, 68-69:375-382.

25. Urade $Y$, Hayaishi O: Biochemical, structural, genetic, physiological, and pathophysiological features of lipocalin-type prostaglandin D synthase. Biochim Biophys Acta 2000, 1482:259-271.

26. Kanaoka $Y$, Urade $Y$ : Hematopoietic prostaglandin D synthase. Prostaglandins Leukot Essent Fatty Acids 2003, 69:163-167.

27. Shimizu T, Yamashita A, Hayaishi O: Specific binding of prostaglandin D2 to rat brain synaptic membrane. Occurrence, properties, and distribution. J Biol Chem 1982, 257:13570-13575.
28. Nishida Y, Yoshioka M, St-Amand J: The top 10 most abundant transcripts are sufficient to characterize the organs functional specificity: evidences from the cortex, hypothalamus and pituitary gland. Gene 2005, 344:133-141.

29. Adams IR, McLaren A: Sexually dimorphic development of mouse primordial germ cells: switching from oogenesis to spermatogenesis. Development 2002, 129:1155-1164

30. Wilhelm D, Palmer S, Koopman P: Sex determination and gonadal development in mammals. Physiol Rev 2007, 87:1-28.

31. Mohri I, Taniike M, Taniquchi H, Kanekiyo T, Aritake K, et al: Prostaglandin D2-mediated microglia/astrocyte interaction enhances astrogliosis and demyelination in twitcher. J Neurosci 2006, 26:4383-4393.

32. Michimata T, Tsuda H, Sakai M, Fujimura M, Nagata K, et al: Accumulation of CRTH2-positive T-helper 2 and T-cytotoxic 2 cells at implantation sites of human decidua in a prostaglandin D(2)-mediated manner. Mol Hum Reprod 2002, 8:181-187.

33. Shiue $Y L$, Chen $L R$, Chen $C F$, Chen $Y L$, Ju JP, et al: Identification of transcripts related to high egg production in the chicken hypothalamus and pituitary gland. Theriogenology 2006, 66:1274-1283.

34. Chen LR, Lee SC, Lin YP, Hsieh YL, Chen YL, et al: Prostaglandin-D synthetase induces transcription of the LH beta subunit in the primary culture of chicken anterior pituitary cells via the PPAR signaling pathway. Theriogenology 2010, 73:367-382.

35. Bennegard B, Hahlin M, Hamberger L: Luteotropic effects of prostaglandins 12 and D2 on isolated human corpora luteum. Fertil Steril 1990, 54:459-464.

36. Aritake $K$, Kado $Y$, Inoue $T$, Miyano M, Urade $Y$ : Structural and functional characterization of $\mathrm{HQL}-79$, an orally selective inhibitor of human hematopoietic prostaglandin D synthase. J Biol Chem 2006, 281:15277-15286.

37. Matsushita N, Hizue M, Aritake K, Hayashi K, Takada A, et al: Pharmacological studies on the novel antiallergic drug HQL-79: I. Antiallergic and antiasthmatic effects in various experimental models. Jpn J Pharmacol 1998, 78:1-10.

38. Satoh T, Moroi R, Aritake K, Urade Y, Kanai Y, et al: Prostaglandin D2 plays an essential role in chronic allergic inflammation of the skin via CRTH2 receptor. J Immunol 2006, 177:2621-2629.

39. Malki S, Berta P, Poulat F, Boizet-Bonhoure B: Cytoplasmic retention of the sex-determining factor SOX9 via the microtubule network. Exp Cell Res 2005, 309:468-475.

40. Cherradi N, Chambaz EM, Defaye G: Organization of 3 betahydroxysteroid dehydrogenase/isomerase and cytochrome P450scc into a catalytically active molecular complex in bovine adrenocortical mitochondria. J Steroid Biochem Mol Biol 1995, 55:507-514.

41. Moniot B, Boizet-Bonhoure B, Poulat F: Male specific expression of lipocalin-type prostaglandin D synthase (CPTGDS) during chicken gonadal differentiation: relationship with cSOX9. Sex Dev 2008, 2:96-103.

42. Albrecht KH, Eicher EM: Evidence that Sry is expressed in pre-Sertoli cells and Sertoli and granulosa cells have a common precursor. Dev Biol 2001, 240:92-107.

43. Schlessinger D, Garcia-Ortiz JE, Forabosco A, Uda M, Crisponi L, et al: Determination and Stability of Gonadal Sex. J Androl 2009.

44. Wilhelm D, Washburn LL, Truong V, Fellous M, Eicher EM, et al: Antagonism of the testis- and ovary-determining pathways during ovotestis development in mice. Mech Dev 2009, 126:324-336.

45. Piprek RP: Molecular mechanisms underlying female sex determinationantagonism between female and male pathway. Folia Biol (Krakow) 2009, 57:105-113.

46. Komar CM, Braissant O, Wahli W, Curry TE Jr: Expression and localization of PPARs in the rat ovary during follicular development and the periovulatory period. Endocrinology 2001, 142:4831-4838.

47. Komar CM: Peroxisome proliferator-activated receptors (PPARs) and ovarian function-implications for regulating steroidogenesis, differentiation, and tissue remodeling. Reprod Biol Endocrinol 2005, 3:41.

48. Kumar TR, Wang Y, Lu N, Matzuk MM: Follicle stimulating hormone is required for ovarian follicle maturation but not male fertility. Nat Genet 1997, 15:201-204.

49. Richards JS, Pangas SA: The ovary: basic biology and clinical implications. J Clin Invest 2010, 120:963-972.

50. Lu C, Yang W, Chen M, Liu T, Yang J, et al: Inhibin A inhibits folliclestimulating hormone (FSH) action by suppressing its receptor expression in cultured rat granulosa cells. Mol Cell Endocrinol 2009, 298:48-56. 
51. Minegishi T, Hirakawa T, Kishi H, Abe K, Abe Y, et al: A role of insulin-like growth factor I for follicle-stimulating hormone receptor expression in rat granulosa cells. Biol Reprod 2000, 62:325-333.

52. Bakke M, Zhao L, Hanley NA, Parker KL: SF-1: a critical mediator of steroidogenesis. Mol Cell Endocrinol 2001, 171:5-7.

53. Jeyasuria P, Ikeda Y, Jamin SP, Zhao L, De Rooij DG, et al: Cell-specific knockout of steroidogenic factor 1 reveals its essential roles in gonadal function. Mol Endocrinol 2004, 18:1610-1619.

54. Yazawa T, Inanoka Y, Okada R, Mizutani T, Yamazaki Y, et al: PPAR-\{gamma\} Coactivator-1\{alpha\} Regulates Progesterone Production in Ovarian Granulosa Cells with SF-1 and LRH-1. Mol Endocrinol .

55. Prosperi JR, Robertson FM: Cyclooxygenase-2 directly regulates gene expression of P450 Cyp19 aromatase promoter regions pll, pl.3 and pl.7 and estradiol production in human breast tumor cells. Prostaglandins Other Lipid Mediat 2006, 81:55-70

56. Matsushita N, Aritake K, Takada A, Hizue M, Hayashi K, et al: Pharmacological studies on the novel antiallergic drug HQL-79: II. Elucidation of mechanisms for antiallergic and antiasthmatic effects. Jpn J Pharmacol 1998, 78:11-22.

57. Ueno N, Takegoshi Y, Kamei D, Kudo I, Murakami M: Coupling between cyclooxygenases and terminal prostanoid synthases. Biochem Biophys Res Commun 2005, 338:70-76.

58. Liu M, Eguchi N, Yamasaki Y, Urade $Y$, Hattori $N$, et al: Protective role of hematopoietic prostaglandin $\mathrm{D}$ synthase in transient focal cerebral ischemia in mice. Neuroscience 2009, 163:296-307.

59. Liu M, Eguchi N, Yamasaki Y, Urade Y, Hattori N, et al: Focal cerebral ischemia/reperfusion injury in mice induces hematopoietic prostaglandin D synthase in microglia and macrophages. Neuroscience 2007, 145:520-529.

60. Gao W, Schmidtko A, Lu R, Brenneis C, Angioni C, et al: Prostaglandin D(2) sustains the pyrogenic effect of prostaglandin E(2). Eur J Pharmacol 2009, 608:28-31.

61. Mohri I, Aritake K, Taniguchi H, Sato Y, Kamauchi S, et al: Inhibition of prostaglandin D synthase suppresses muscular necrosis. Am J Pathol 2009, 174:1735-1744.

62. Trivedi SG, Newson J, Rajakariar R, Jacques TS, Hannon R, et al: Essential role for hematopoietic prostaglandin D2 synthase in the control of delayed type hypersensitivity. Proc Natl Acad Sci USA 2006, 103:5179-5184.

63. Lecureuil C, Fontaine I, Crepieux P, Guillou F: Sertoli and granulosa cellspecific Cre recombinase activity in transgenic mice. Genesis 2002 33:114-118.

doi:10.1186/1757-2215-4-3

Cite this article as: Farhat et al:: Hematopoietic-Prostaglandin D2 synthase through PGD2 production is involved in the adult ovarian physiology. Journal of Ovarian Research 2011 4:3.

\section{Submit your next manuscript to BioMed Central and take full advantage of:}

- Convenient online submission

- Thorough peer review

- No space constraints or color figure charges

- Immediate publication on acceptance

- Inclusion in PubMed, CAS, Scopus and Google Scholar

- Research which is freely available for redistribution

Submit your manuscript at www.biomedcentral.com/submit
CioMed Central 